\title{
PEQUENAS EMPRESAS E DEMOCRATIZAÇÃO NO BRASIL (1978-1990) ${ }^{1}$
}

\author{
SMALL BUSINESS AND DEMOCRATISATION IN BRAZIL (1978-1990)
}

\author{
William R. Nylen ${ }^{*}$ \\ (Tradução ${ }^{2}$ de Daniel Gustavo Fleig ${ }^{* *}$ )
}

\begin{abstract}
Resumo
Este artigo explora a política da não-elite do capital ${ }^{3}$ - ou das micro, pequenas e médias empresas (MPMEs) - na época da transição do regime militar para a democracia contemporânea no Brasil. Descreve as relações e interações políticas entre ativistas políticos das MPMEs e suas organizações de ação coletiva, por um lado, e instituições políticas formais (agências estatais, formuladores de políticas, partidos políticos etc.) e organizações de ação coletiva dominadas por empresas da elite empresarial, por outro. O artigo argumenta que a não-elite do capital é um componente há muito ignorado dos setores populares economicamente explorados, socialmente subordinados e excluídos politicamente, em toda a América Latina. Embora os micro, pequenos e médios empresários possam ser membros da "classe empresarial", seus interesses não devem ser confundidos com aqueles que professam representálos em organizações dominadas por elites empresariais (associações do topo - peak associations - e instituições corporativas "representativas" de longa data) ou por burocratas nomeados politicamente em agências estatais, que afirmam levar os interesses de "seus clientes" no coração. O artigo demonstra como os esforços das lideranças das associações do topo no Brasil para consolidar a "unidade empresarial”, no período de análise, ajudaram a destruir um movimento social promissor do associativismo da não-elite do capital nos finais dos anos 1970 até o início dos anos 1990. Sugere-se que, quando permitido florescer, esse ativismo pode gerar benefícios positivos para as MPMEs que não seriam possíveis de outra maneira, especialmente se deixadas para as organizações tradicionais dominadas pela elite do capital. Analiticamente, este estudo de caso ilustra a utilidade do conceito de Sidney Tarrow (1994) de um "ciclo de protesto", mostrando como a história da ascensão e a subsequente queda da ação coletiva da não-elite do capital no Brasil podem ser vistas como partes de um processo cíclico, mais universal, de reformismo induzido por uma crise político-institucional, seguido de eventual enrijecimento das estruturas políticas.
\end{abstract}

Palavras-chave: Democratização. Sociedade Civil. Micro, Pequena e Média Empresa. Política Empresarial.

1 Artigo não publicado, originalmente apresentado no dia 27 de outubro de 1990, no painel Organized Interests, Political Participation, and the State in Brazil, na reunião do New England Council of Latin American Studies, Durham, New Hampshire. Atualizado em 1997.

* Professor de Ciência Política e Diretor do Programa de Estudos Internacionais na Stetson University, (DeLand, Flórida, EUA). Ele é autor de Elitist Democracy vs. Participatory Democracy: Lessons from Brazil (2003) assim como de vários artigos e capítulos de livros sobre a política e a política econômica no Brasil e em Moçambique. Possui doutorado em Ciência Política (política comparada) pela Columbia University (Nova Iorque), mestrado em estudos latino-americanos e economia internacional pela Johns Hopkins School of Advanced International Studies (Washington) e bacharelado em Ciência Política pela University of California at Berkeley. E-mail: wnylen@stetson.edu

2 Tradução certificada pelo Centro de Assessoria de Publicação Acadêmica (Capa) da Universidade Federal do Paraná.

${ }^{* *}$ Professor de Gestão e Empreendedorismo na Universidade Federal do Paraná (UFPR - Setor Litoral - Matinhos), com graduação em Administração (UFSM), mestrado em Administração (UFLA) e doutoramento em Sociologia (UFPR). E-mail: fleig@ufpr.br.

3 Nota do tradutor: no original do artigo em inglês, o termo apresentado é no-elite capital. Com esse termo, Nylen busca um contraste com as grandes empresas, com destaque para a dimensão política do desenvolvimento brasileiro. Neste sentido, as grandes empresas (nacionais, estatais e estrangeiras) representam o grande capital econômico e, no âmbito político, a elite do capital. Portanto, as chamadas micro, pequena e médias empresas representam o pequeno capital econômico, constituindo, na esfera política, a não-elite do capital. 


\begin{abstract}
This article explores the politics of the non-elite capital - or of micro, small and medium-sized enterprises (MSMEs), at the time of the transition from the military regime to contemporary democracy in Brazil. It describes the relations and political interactions between MSMEs political activists and their collective action organizations, on the one hand, and formal political institutions (state agencies and policy makers, political parties, etc.) and collective action organizations dominated by business elite companies, on the other hand. The present work argues that the non-elite capital is a long-ignored component of the economically exploited, socially subordinated and politically excluded popular sectors across Latin America. Although micro, small and medium-sized entrepreneurs may be members of the "business class," their interests should not be confused with those who profess to represent them in organizations dominated by business elites (top associations - "peak associations" - and corporatist institutions' "representatives") or by politically appointed bureaucrats in state agencies, who claim to have the best interests of "their clients" at heart. The article demonstrates how the efforts of the leaders of the top associations in Brazil to consolidate the "business unity", during the analysis period, helped to destroy a promising social movement of non-elite capital associations in the late 70s until the beginning of the 1990s. It is suggested that, when allowed to flourish, this activism can generate positive benefits for MSMEs that would not be possible otherwise, especially if left to traditional organizations dominated by the capital elite. Analytically, this case study illustrates the usefulness of Sidney Tarrow's (1994) concept of a "protest cycle", showing how the history of the rise and subsequent fall of collective action by the non-elite capital in Brazil can be seen as parts of a cyclical, more universal process, of reformism induced by a political-institutional crisis, followed by eventual rigidity of the following political structures.
\end{abstract}

Keywords: Democratization. Civil Society. Micro, Small and Medium Business. Business policy.

\title{
Introdução
}

Os estudiosos da democratização na América Latina há muito reconhecem a importância da classe empresarial em ajudar, dificultar ou influenciar processos de mudança política. ${ }^{4}$ Isso não deveria causar surpresa. Os estudiosos marxistas sempre insistiram em uma análise minuciosa, embora às vezes excessivamente mecanicista, das relações estado-capital. Análises mais sofisticadas e empíricas da política da classe empresarial - relações entre elites econômicas e instituições políticas e, igualmente importante, entre os próprios setores econômicos (ou "frações de classe") - têm sido um dos pilares do estudo da América Latina nos Estados Unidos, pelo menos desde o trabalho inovador de estudiosos neomarxistas e teoria da dependência, como Guillermo O’Donnell, Celso Furtado, Fernando Cardoso e Enzo Faletto e Peter Evans. Os não marxistas também reconheceram a importância de estudar a política de classe empresarial, como atestam os trabalhos seminais de Simon Schwartzman, Philippe Schmitter, Peter McDonough e outros.

Neste artigo, não questiono a sabedoria de estudar a política da classe empresarial, nem questiono a maior parte das descobertas da vasta literatura gerada ao longo dos anos. Em vez disso, busco acrescentar uma nova dimensão a essa literatura, que estava em grande parte ausente há dez anos, quando empreendi a pesquisa na qual este artigo se baseia e que permanece pouco estudada até hoje (com a exceção parcial de alguns trabalhos sobre a classe empresarial no México contemporâneo). ${ }^{5}$

\footnotetext{
4 Veja, por exemplo, Ernest Bartell e Leigh A. Payne em Business and Democracy in Latin America (1995), Leigh A. Payne em Brazilian Industrialists and Democratic Change (1994), Douglas A. Chalmers, Maria do Carmo Campello de Souza e Atilio A. Boron em The Right and Democracy in Latin America (1992) e David G. Becker em Business Associations in Latin America: the Venezuelan Case Comparative Political Studies (1990).

5 Blanca Heredia em Profits, Politics, and Size: The Political Transformation of Mexican Business in Chalmers (1992) e Kenneth C. Shadlen no artigo Small Industry and the Mexican Left: Neoliberalism, Corporatism, and Dissident Populism (1997).
} 
Este artigo explora esse aspecto da política de classe empresarial que chamo de nãoelite do capital, ou micro, pequenas e médias empresas (MPMEs). ${ }^{6}$ Essa dimensão que falta na literatura inclui relações e interações políticas entre ativistas políticos do MPME e suas organizações de ação coletiva, por um lado, e instituições políticas formais (por exemplo: agências estatais e formuladores de políticas, partidos políticos etc.) e organizações de ação coletiva dominadas por empresas da elite empresarial - por exemplo: associações "do topo" (peak associations) e instituições corporativas "representativas" de longa data -, por outro.

Argumento que a não-elite do capital é um componente há muito ignorado dos setores populares economicamente explorados, socialmente subordinados e excluídos politicamente, em toda a América Latina. ${ }^{7}$ Embora micro, pequenos e médios empresários possam ser membros da "classe empresarial", seus interesses não devem ser confundidos com aqueles que professam representá-los em organizações dominadas por elites empresariais ou por burocratas nomeados politicamente em agências estatais que afirmam levar os interesses de "seus clientes" no coração. "A classe empresarial", afinal, é uma abstração analítica. A unidade da classe empresarial e a representação unitária de toda a classe empresarial são apenas maneiras agradáveis e igualmente abstratas de descrever o domínio político das grandes empresas sobre o capital que não é de elite. No entanto a literatura existente muitas vezes opta pelo uso mais amplo do termo "classe empresarial" ou escolhe se concentrar exclusivamente nas "elites empresariais". De qualquer maneira, uma importante dimensão da política - a subjugação de um setor social significativo - é ignorada.

Para ilustrar meu argumento, demonstrarei como os esforços das lideranças das associações tradicionais das empresas ("do topo") no Brasil, para consolidar a "unidade empresarial", ajudaram a destruir um movimento social promissor do associativismo do capital não pertencente à elite, durante o final da década de 1970 até o início dos anos 1990. Claramente, outros fatores também foram importantes para explicar esse fracasso na consolidação do ativismo coletivo: a extrema heterogeneidade da "classe" de micro, pequenos e médios empresários, a imersão total frequentemente observada dos empresários de pequeno porte em seus negócios e sua consequente falta de tempo para participar politicamente, a cultura política mais generalizada do Brasil de passividade política etc. Ilustrarei, no entanto, que o capital da elite

$6 \mathrm{O}$ tamanho da empresa é uma notação abreviada popular (embora de modo algum não problemática) para distinguir entre capitais de elite e de não-elite. Nas décadas de 1960 e 1970, de acordo com Peter Evans (1979), as grandes empresas constituíam parte integrante da tríplice aliança dominante de capitais de Estado, multinacionais e grandes elites domésticas. Para definições semelhantes, ver Eli Diniz e Renato Raul Boschi em Empresariado Nacional e Estado no Brasil (1978) e também R.R. Boschi Elites Industriais e Democracia (1979). Para abordagens mais recentes e definições semelhantes de elites empresariais e não-elites, consulte Payne em Brazilian Industrialists and Democratic Change (1994), especificamente o capítulo 1, e também Henrique Rattner em Pequena Empresa: O Comportamento Empresarial na Acumulação e Luta pela Sobrevivência, volumes 1 e 2 (1985).

7 Alguns podem se opor a ver donos de empresas colocados na categoria do setor popular. Mas aceito a seguinte definição: Na América Latina, o "popular" é uma mistura de elementos socioeconômicos, políticos e culturais. O "popular" abrange a pobreza, mas não se limita a ela. Incorporando também uma dimensão política e cultural, o "popular" inclui grupos de classe média mobilizados não tanto por demandas estritamente econômicas quanto por pedidos de democratização, liberdades públicas e direitos de cidadania. Ver Carlos Vilas em Participation, Inequality, and the Whereabouts of Democracy (1997). 
organizado foi crucial para garantir que os cerca de 99\% dos empresários privados brasileiros oficialmente identificados como "micro, pequenos ou médios" em 1980 (ou seja, empresas do setor comercial e de serviços com menos de 100 funcionários e empresas industriais com menos de 250 ) - que empregavam cerca de $84 \%$ da força de trabalho e ganhavam cerca de $70 \%$ da renda total - perderam a oportunidade de escolher entre organizações representativas estabelecidas por pequenos empresários como eles e as organizações tradicionais que, por praticamente todas as contas objetivas, representam apenas as empresas maiores e mais bem conectadas ("o capital da elite") em apenas alguns setores da economia. ${ }^{8}$

Isso aconteceu no Brasil em "vias de democratização" - o maior país da América Latina e o país com a nona maior economia do mundo - e ninguém escreveu sobre isso. Isso, por si só, traz uma importante contribuição para a literatura. Eu vou adiante, no entanto, argumentando que a falta dessa dimensão da política de classe empresarial faz com que os observadores subestimem até que ponto a atual política de classe empresarial brasileira pode ser caracterizada como abertamente antidemocrática (hostil à "inclusão" e à "contestação" democrática). Pode parecer desnecessário acrescentar mais uma voz ao coro de críticas a respeito de "defeitos congênitos" elitistas do processo de democratização do Brasil. ${ }^{9}$ Mas o registro histórico exige isso, assim como as reivindicações de muitas elites empresariais do Brasil de que elas são uma força positiva para a democracia.

Além de sua relevância para o desenvolvimento brasileiro e para quem estuda o Brasil, este também é um estudo de caso das possibilidades e limitações do ativismo político da não-elite capital nas economias caracteristicamente oligopolistas e estatizantes da América Latina e suas políticas elitistas de "democratização". Ele sugere que, em condições favoráveis, esse ativismo pode gerar benefícios positivos para as pequenas e médias empresas que não seriam possíveis de outra maneira, especialmente se deixadas para as organizações tradicionais dominadas pela elite. Em condições desfavoráveis, entretanto, este estudo de caso sugere que é provável que o capital organizado da elite assuma uma boa parte da culpa.

\section{Três ondas de ativismo da Não-Elite do Capital na "Democratização do Brasil” (1978-1990)10}

O princípio básico por trás do ativismo das pequenas empresas no Brasil sempre foi "tratamento diferenciado" ou, como um proponente disse, "tratamento desigual para desiguais"11. O conceito não é diferente do de "ação afirmativa" nos Estados Unidos, em que considerações especiais são tidas como apropriadas para um determinado grupo, a fim de compensar

\footnotetext{
8 Dados do censo oficial da FIBGE dos setores de indústria, comércio e serviços (1980).

9 Tais vozes incluem as numerosas análises de Francis Hagopian das "elites tradicionais", incluindo Traditional Power Structures and Democratic Governance in Latin America (1996) e Guillermo O'Donnell em Transitions, Continuities, and Paradoxes (1992).

10 Para uma descrição e análise mais detalhadas desses eventos até 1990, consulte William R. Nylen em Small Business Owners Fight Back: Non-elite Capital Activism in Democratizing Brazil (1978-1990) publicado em 1992.

11 Para Helio Beltrão (1984, p. 97), "não há livre empresa sem pequena empresa”.
} 
desigualdades ou preconceitos contra esse grupo que foram estruturados na sociedade. No Brasil, ativistas de pequenas empresas e seus apoiadores discutiram em momentos diferentes a implementação desse princípio em seu nome: dentro da estrutura oficial corporativista de associações empresariais, no sistema jurídico referente às responsabilidades fiscais e à regulamentação das empresas, no conjunto de prioridades de desenvolvimento estabelecidas pelo Estado e implementadas principalmente na forma de acesso ao crédito subsidiado pelo Estado.

A Primeira Onda: Antes de 1978, não existia ação política coletiva de pequenos empresários no Brasil. Pequenas e médias empresas receberam tratamento diferenciado, a partir de iniciativas do Estado para estimular o emprego e a modernização produtiva, principalmente por meio da criação de linhas de crédito com juros baixos e várias reduções e isenções de impostos. ${ }^{12}$ Em 1972, o governo militar criou o Centro Brasileiro de Assistência às Pequenas e Médias Empresas (Cebrae) para facilitar e coordenar esses esforços nos níveis nacional, estadual e municipal. ${ }^{13}$ Tais políticas não incluíram a organização e mobilização de sua clientela ${ }^{14}$ e uma porcentagem significativa de seus fundos era rotineiramente canalizada para as maiores e mais lucrativas empresas tecnicamente mais produtivas. ${ }^{15}$ No entanto as políticas estabeleceram o conceito de pequenas e médias empresas (PMEs) como uma categoria econômica e social distinta, fornecendo, assim, a base para a identidade coletiva e os esforços subsequentes de organização e mobilização.

O primeiro desses esforços ocorreu em 1978, no centro industrial de São Paulo. Três associações industriais de pequeno e médio porte foram formadas deliberadamente independente das associações comerciais corporativas oficiais (sindicatos) e de sua poderosa organização da elite do capital, a Federação da Indústria do Estado de São Paulo $(\text { Fiesp })^{16}$. Essa configuração precedente pode ser delineada por seis principais causas.

12 As microempresas (ou Micro-sized businesses) não foram oficialmente distinguidas das pequenas empresas até o início dos anos 1980.

$13 \mathrm{Em} \mathrm{1990,} \mathrm{“a} \mathrm{Lei} \mathrm{no} 8.029$ [...] autorizava [o Cebrae] a desvincular-se da administração pública e estabelecia critérios para a arrecadação de recursos, que passaram a vir de uma alíquota de $0,3 \%$ cobrada sobre as remunerações pagas pelas empresas contribuintes do Sesi/Senai e Sesc/Senac aos seus empregados. Dessa forma, o Cebrae se transformou em serviço social autônomo. Em 9 de outubro, o Decreto $\mathrm{n}^{\circ} 99.570$ alterou a sua denominação para Serviço Brasileiro de Apoio às Micro e Pequenas Empresas, o Sebrae com "S", que passa a fazer parte do chamado Sistema S, que inclui Senai, Sesi, Senac, Sesc, Senar, Senat, Sest, Sescoop, entre outros." [Fonte: https://memorial. sebrae.com.br/historia/?ano=1990]

14 Como o ex-diretor de operações do Cebrae (1974-1978), Afonso Otávio Cozzi, colocou em uma entrevista concedida ao autor em 15 de julho de 1986: (...) o trabalho que fizemos no Cebrae, foi feito diretamente pelo governo para os empresários. Portanto, não dialogamos com pequenos empresários. [...] Éramos bastante fortes, até um pouco autoritários.

15 Essa é uma das conclusões de Eli Diniz e Renato Raul Boschi no artigo O Programa de Apoio à Pequena e Média Empresas no BNDES: Análise, Avaliação e Perspectivas, presente na obra A Pequena e Média Empresa no Atual Modelo de Desenvolvimento Econômico (1980). Esse ainda era o caso no final de 1997. Veja Miséria e Classe Média na Folha de São Paulo (1997).

16 As novas organizações foram: Associação de Pequenas e Médias Empresas e Centro de Estudos (Acempeme), Associação Nacional de Pequenas e Médias Indústrias (Anapemei) e Associação Brasileira de Pequenas e Médias Indústrias (Abrapemi). 
A primeira e mais imediata causa foi o resultado de negociações salariais após as vigorosas greves de metalúrgicos em 1978 e 1979. ${ }^{17}$ Vários pequenos industriais expressaram publicamente sua raiva por terem sido ignorados pelos negociadores da Fiesp (todos representando as maiores empresas do setor). Como resultado dessa falta de atenção, eles alegaram que as pequenas empresas em mercados concorrenciais, (price taking small firms) mais intensivas em mão de obra e famintas de capital, estavam sendo forçadas a aceitar um acordo salarial que não podiam pagar. As grandes empresas, por outro lado, eram geralmente "fabricantes de preços", oligopolistas e intensivas em capital, que podiam facilmente repassar preços mais altos aos seus clientes. ${ }^{18}$

Essa percepção de falta de representação no processo de negociação salarial era indicativa, na opinião dos fundadores dessas associações, de uma falta de representação mais geral na estrutura da Fiesp como um todo. De fato, uma sensação de falta de representatividade da Fiesp já havia surgido entre pelo menos alguns pequenos industriais em São Paulo e nos arredores.

Em 1975, por exemplo, um grupo de cerca de 25 pequenos industriais da cidade de Campinas, interior de São Paulo, apresentou um documento de 23 páginas à diretoria da Fiesp intitulado "O pequeno industrial é, acima de tudo, um forte ... candidato a um ataque cardíaco!" Enumerando muitas das queixas comumente associadas ao status de pequeno produtor - escassez de capital de giro devido ao fato de ser espremido entre fornecedores e clientes oligopolistas de estabelecimento de preços, regulamentos burocráticos excessivos e encargos tributários etc. - e descrevendo um programa de extensão de assistência do Estado aos pequenos industriais, o documento terminou com uma crítica direta à falta de representação da Fiesp: ... NÃO EXISTE COMUNICAÇÃO COM as indústrias de pequeno e médio porte, ou seja, comunicaçõessuficientesnãoestãochegandoaessasindústrias. Agora, semtercanaisapropriadosde comunicação com órgãos governamentais, entidades representativas e outras agências envolvidas com as quais possa chegar a indústrias menores, pelo menos periodicamente, seja qual for a boa iniciativa, seja qual for o programa de ajuda, assistência e ajuda a essas empresas serão natimortas. ${ }^{19}$

Diniz e Boschi (1978, p. 178) confirmaram essa suspeita, argumentando que "a liderança política da Fiesp em meados da década de 1970 é mantida nas mãos de grandes empresários, que podem, quando for conveniente, fazer uso da força representada pelo contingente numérico de pequenas e médias empresas". Empresários e empresas que não pertencem à categoria da elite de empresas maiores foram formalmente "representados", mas não foram realmente ouvidos por seus supostos líderes. Talvez como resultado, a maioria dos empresários ignorou as organizações oficiais de classe empresarial. Menos de 10\% das 160.887 indústrias existentes, segundo o censo industrial de 1970, eram membros registrados de seu sindicato e

17 Veja Margaret E. Keck em The Workers' Party and Democratization in Brazil (1992), especificamente o capítulo 4. 18 O presidente de quatro mandatos da Anapemei e proprietário de uma empresa com 135 funcionários, Claudio Rubens, disse-me, em uma entrevista em 4 de julho de 1988, que essa reação decorreu do fato de que os custos de mão de obra para pequenas e médias empresas industriais representavam tipicamente $17 \%$ a $35 \%$ dos custos totais de produção, enquanto o valor respectivo de um fabricante/montador de automóveis, por exemplo, era de apenas $11 \%$. 19 Wlademir Righetto et al. O pequeno industrial é, antes de tudo, um forte ... candidato ao enfarte! (1975). 
não mais de $6 \%$ haviam ingressado em uma "associação paralela" ${ }^{20}$ Essa falta de interesse se correlacionou diretamente com o tamanho da empresa. Um estudo sobre a participação nos sindicatos industriais de São Paulo e nas filiais locais do Centro de Indústrias do Estado de São Paulo (Ciesp), no início dos anos 1970, descobriu que “a representação tende a crescer com o tamanho das firmas-membros", assim como a participação nas posições de liderança ${ }^{21}$

Esse sentimento crescente das falhas da Fiesp como entidade representativa coincidiu com a terceira causa subjacente dessa onda inicial de associativismo de pequenas empresas: uma maior conscientização pública das pequenas empresas como contribuinte positivo para o desenvolvimento econômico do Brasil. Essa foi uma imagem promovida em meados da década de 1970 pelo Cebrae, em rápida expansão, e pelo Banco Nacional de Desenvolvimento Econômico, ${ }^{22}$ não apenas para estimular a atividade fora dos "altos comandos dominantes" da economia (estimulando a criação de empregos e uma maior base tributária), mas também para convencer os pequenos empresários e outros que o Estado se importava com sua inclusão no modelo de desenvolvimento econômico. ${ }^{23}$ Novas linhas de crédito oficial para MPMEs foram abertas e promovidas pelo Cebrae com grande alarde. Os relatórios do censo foram amplamente divulgados, mostrando que $99 \%$ de todas as indústrias, $99,9 \%$ de todas as empresas comerciais e 99,9\% de todas as empresas do setor de serviços no Brasil eram "micro, pequenas ou médias".

Enquanto o país estava dando os primeiros passos em seu processo prolongado de democratização (abertura) - com as eleições locais e do Congresso já tendo ocorrido - muitos dos fundadores dessa primeira onda de associativismo de pequenas e médias empresas viram nessas figuras e na retórica do governo uma noção do potencial de um lobby organizado em nome de pequenas e médias empresas. Esse sentido foi bastante aprimorado quando, em 1979, o general Golbery, principal assessor do presidente Geisel e autor da abertura, manifestou publicamente interesse em promover o desenvolvimento de pequenas empresas e, ainda mais importante, sua participação política. Em uma ação destinada a enfurecer a liderança da Fiesp (que estava fazendo todos os esforços para contestar legalmente e deslegitimar as novas associações), ele se encontrou pessoalmente com vários dos fundadores das novas associações

20 Archibaldo Figueira (Assessoria Parlamentar do CEBRAE), no artigo O Legislativo e o Sistema de Pequena e Média Empresa (1986, p. 8). A divisão do trabalho político entre sindicatos e associações setoriais "paralelas" é descrita como "mais complementar do que conflituosa" por Diniz \& Boschi (1978). Ver também Peter Kingstone em Shaping Business Interests: the Politics of Neoliberalism in Brazil, 1985-1992, (1994).

21 Oracy Nogueira et al. (1975, p. 35). O Ciesp era uma estrutura paralela, legalmente autônoma dos regulamentos do Estado, ao lado da Fiesp. Sua liderança, no entanto, era a mesma da Fiesp. Para Payne (1994, p. 243), "a FIESP agrada mais aos industriais conservadores de grandes empresas, independentemente da nacionalidade".

22 Criado em 1952, o BNDE passou a ter a denominação de Banco Nacional de Desenvolvimento Econômico e Social (BNDES) em 1982.

23 Entrevista do autor com o Dr. Afonso Otávio Cozzi, ex-diretor de Operações do CEBRAE (1974-1978), 15 de julho de 1986, Belo Horizonte.

24 Para comércio e serviços: micro = 0-9 funcionários, pequeno = 10-49 e médio = 50-99; para a indústria: micro $=0-9$, pequeno $=10-99$ e médio $=99-249($ FIBGE, 1970 $)$ 
de São Paulo para discutir suas preocupações e interesses. ${ }^{25} \mathrm{~A}$ democratização e essa brecha intraelite, portanto, forneceram a "estrutura de oportunidades" para a ação coletiva da nãoelite do capital, que antes não estava disponível sob estruturas autoritárias mais rígidas ${ }^{26}$. Uma quinta causa subjacente da ação coletiva de pequenas empresas foi a descoberta, por parte de vários dos fundadores dessas primeiras associações, da existência de associações autônomas de pequenas empresas em outros países. Vários chegaram a visitar diversas associações de pequenas empresas na Itália antes de começar a criar as suas próprias.

Finalmente, o fato de a liderança da Fiesp estar passando pelo primeiro desafio eleitoral nos quase 50 anos de história da organização significava que a liderança emergente de pequenas indústrias detinha um poder de barganha sem precedentes com os líderes da oposição. Pelo menos dois líderes fundadores fizeram acordos para apoiar o concorrente, que findou por vencer, em troca das promessas de que a Fiesp prestaria mais atenção às pequenas empresas no futuro.

Essa "primeira onda" de ação coletiva de pequenas empresas produziu vários resultados benéficos para pequenas empresas industriais em São Paulo. Primeiro, as negociações salariais no setor de metalurgia foram alteradas, permitindo que empresas menores pagassem aumentos percentuais relativamente menores. O processo de negociação foi alterado para incluir um conselho de sindicatos de membros (onde as pequenas empresas têm uma voz potencialmente mais significativa) e um grupo técnico que consulta e estuda as necessidades de uma seção muito mais ampla das firmas-membro.

Segundo, a Fiesp criou um Departamento de Assistência à Média e Pequena Indústria para fornecer serviços e consultoria especiais a seus membros menores (ao mesmo tempo, tornou-se uma influência essencialmente controladora na diretoria da filial estadual do Cebrae). Finalmente, pelo menos duas das três associações autônomas originais persistiram até o final da década de 1980 e, embora afetada por uma baixa e instável adesão de membros, eles ainda forneciam serviços e um grau de representação que até então era inexistente (especialmente porque a mídia local costumava se voltar para eles, para "opiniões alternativas", sobre questões do dia).

Em uma aparente tentativa de evitar uma divisão semelhante nas fileiras do setor de comércio de São Paulo (onde, em 1975, 99,87\% das empresas formais eram consideradas pequenas e médias, empregando $92,57 \%$ da força de trabalho do setor e gerando $89,85 \%$ de seu total de receitas), a Associação de Comércio de São Paulo (ACSP) adotou plenamente a causa ainda não articulada da representação de pequenas e médias empresas desde $1977^{27}$. Em conjunto com o

25 Entrevistas do autor com Braulio Cesar Jordão Machado, fundador e primeiro presidente da Acepeme-SP, em 6 de novembro de 1989; e com Wlademir Righetto, fundador e primeiro presidente da Acepeme-Campinas, em 25 de março de 1988 e 11 de novembro de 1989.

26 Para o conceito de "estrutura de oportunidades", veja Sidney Tarrow em Power in Movement: Social Movements, Collective Action and Politics (1994); uma análise semelhante, mas no quadro da teoria dos jogos, pode ser encontrada em Adam Przeworski (1992) em The Games of Transition.

27 Muitos dados do ACSP foram baseados na entrevista do autor com o Dr. Marcel Domingos Solimeo, diretor do Instituto Econômico do ACSP e criador do SMB Council, em 11 de novembro de 1989, em São Paulo. 
Governo do Estado de São Paulo (cujo governador, Paulo Maluf, era ex-presidente da ACSP) e com o Cebrae, a ACSP patrocinou uma série de congressos de três dias para pequenas e médias empresas, começando em 1978. Esses foram amplamente e favoravelmente relatados na mídia e ajudaram a apresentar a ACSP como uma entidade representativa dos interesses das pequenas e médias empresas. Também em 1978, a ACSP criou um Conselho para o Desenvolvimento de Pequenas e Médias Empresas como um canal para a participação das pequenas e médias empresas nos assuntos da ACSP, bem como um fórum para discutir problemas específicos das pequenas e médias empresas. Os líderes da ACSP intensificaram o recrutamento de pequenos empresários para os conselhos distritais, ao mesmo tempo que mantinham controle estrito e centralizado sobre esses conselhos. Muitas outras Associações de Comércio em todo o Brasil acabaram seguindo o exemplo da ACSP, embora geralmente muito depois de o associativismo autônomo do MPME ter se tornado uma ameaça à reivindicação de representação exclusiva.

A Segunda Onda: Uma "segunda onda" de ação coletiva para pequenas empresas ocorreu no início e em meados da década de 1980. Teve como causa imediata o apoio de pequenos empresários e ativistas à criação e implementação do Estatuto da Microempresa, legislação que propunha a eliminação da maioria dos impostos e regulamentações burocráticas das microempresas, como forma de fortalecer seus interesses - suas capacidades de sobrevivência e lucratividade - e como um incentivo para sua "graduação" fora do setor informal. Os debates sobre a criação e implementação do Estatuto da Microempresa, bem como suas contrapartes estaduais e locais, ofereceram muitas oportunidades para os pequenos empresários-ativistas organizarem e fazerem suas vozes serem ouvidas.

Esses ativistas - alguns dos quais fizeram parte da primeira onda de associativismo passaram a falar publicamente da necessidade de "democratizar a economia", mudando o foco exclusivo do Estado em grandes empresas e projetos de desenvolvimento grandiosos e eliminando a considerável pressão fiscal e reguladora do Estado sobre "o cidadão comum"28. Quanto mais eles se manifestavam, mais suas preocupações e interesses assumiam implicações sobre os gritos generalizados antiestado e pró-democratização do período. ${ }^{29}$ Pequenos empresários viram-se elevados, em grande parte por uma imprensa simpática e por políticos da "nova direita", ao status de heróis em sua luta contínua pela sobrevivência, não apenas em um mundo de "capitalismo selvagem", onde grandes empresas públicas e privadas mantinham todas as vantagens do poder de mercado e das conexões políticas, mas também contra uma burocracia sufocante do Estado, com seus vorazes cobradores de impostos e fiscais corruptos. ${ }^{30} \mathrm{O}$ autor do Estatuto da Microempresa, o ministro da desburocratização, Hélio Beltrão, emergiu como o ministro mais

$28 \mathrm{O}$ termo usado no inglês the little guy refere-se ao cidadão comum que não possui riquezas, grandes empresas e tem pouco ou nenhum poder, influência política e econômica.

29 Para "antiestadismo" no Brasil, veja Sebastião Velasco e Cruz Empresários, Economistas e perspectivas da Democratização no Brasil (1988).

30 Na época, o livro de Hernando DeSoto, The Other Path (1989), elogiando o espírito empreendedor e a criatividade de pequenas empresas do setor informal, era um best-seller no Brasil e em toda a América Latina. 
popular do governo e foi mencionado como um provável candidato a presidente. Seu ministério fez campanha em todo o país para a aprovação do estatuto, cortejando ativamente o apoio de entidades tradicionais da classe empresarial, bem como de novas associações autônomas do MPME.

Os opositores do Estatuto das Microempresas eram, principalmente, os ministros de economia do governo, da Receita Federal e da Confederação das Secretarias Econômicas dos Governos Estaduais. Todos temiam a perda de receitas fiscais se o estatuto fosse aprovado. Com o país imerso em sua pior recessão em anos (o início da chamada "Década Perdida"), esses argumentos pró-tributação e seus porta-vozes eram altamente impopulares. Finalmente, a política em torno do Estatuto das Microempresas ilustrou mais uma vez as contradições inerentes às organizações empresariais tradicionais, especialmente as que supostamente representavam os industriais. Essencialmente controladas por grandes empresas nacionais, essas organizações tendiam a relegar o Estatuto da Microempresa a uma pequena preocupação, apesar de ter afetado diretamente a vida da maioria de seus membros.

Vindas dessa luta, mais de cem associações autônomas de micro, pequenas e médias empresas surgiram em todo o país. Muitas surgiram espontaneamente. Muitas outras foram criadas por associações previamente organizadas que se ramificaram nas regiões vizinhas. Em 1985, menos de um ano após a aprovação do Estatuto da Microempresa pelo Congresso, o jornal paulista O Jornal da Tarde (1985, p. 10) declarou, com aprovação, que "uma nova força política está nascendo: os microempresários".

A Associação Comercial e Industrial de Micro e Pequenas Empresas do Vale do Itajaí (Acimpevi) em Blumenau, Santa Catarina, oferece um estudo de caso ilustrativo (com espaço, é claro, para que as circunstâncias locais também se apliquem). No início dos anos 1980, respondendo às crescentes críticas de seus membros e à crescente cobertura da mídia por parte dos MPMEs inspirados no Estatuto da Microempresa, os líderes da Associação de Comércio e Indústria de Blumenau (ACIB) discutiram a criação de uma comissão especial para identificar os problemas das MPMEs de Blumenau e aconselhar os membros interessados sobre a melhor forma de solucionar esses problemas. ${ }^{31}$ A comissão nunca realmente decolou e sua inação foi claramente revelada após as inundações devastadoras da região em julho de 1983. Membros do MPME severamente afetados pediram que o ACIB fizesse lobby por um alívio temporário de sua carga tributária, por linhas especiais de crédito para reconstrução e para obter ajuda para forçar as empresas de seguros relutantes a pagar pelas apólices de alívio de desastres. De acordo com aqueles que acabariam se separando da ACIB, a liderança se opôs a essas medidas. A maioria das grandes empresas, apontaram os dissidentes, ficavam em terrenos mais altos e, portanto, eram comparativamente pouco afetadas pelas inundações.

31 De entrevistas pessoais com Décio Moser, ex-diretor da comissão, em 6 de junho de 1988, e Pedro Cascaes, exmembro da comissão e futuro fundador e presidente da Acimpevi, em 13 de agosto de 1986 e 22 de novembro de 1989. 
Um dos membros da ineficaz Comissão do MPME e cerca de quinze proprietários de pequenas empresas locais decidiram agir por conta própria. Eles propuseram a criação de uma zona de realocação para MPMEs gravemente afetadas e procuraram a reativação de uma Expo ao ar livre, há muito adormecida, de produtos fabricados localmente. Suas propostas foram ignoradas não apenas pela liderança da $\mathrm{ACIB}$, mas também por autoridades locais e estaduais. $\mathrm{O}$ grupo decidiu atuar em um segundo projeto. O primeiro Festival de Verão de Blumenau incluiu cerca de 200 participantes de micro e pequenas empresas e mais de 60.000 visitantes pagantes. Seu sucesso levou o grupo a fundar a Acimpevi, em março de $1984 .{ }^{32}$

$\mathrm{O}$ ACIB respondeu anunciando uma comissão especial de assistência especificamente às microempresas. Essa tentativa de cooptar o programa da Acimpevi e atrapalhar sua fundação foi prejudicada, no entanto, pelo fato de o presidente nomeado da nova comissão ser um grande empresário. No dia da fundação da Acimpevi, o ex-chefe da ineficaz Comissão MPME da ACIB foi forçado a admitir nos jornais locais que não fazia ideia de quantos membros da ACIB eram proprietários de micro ou pequenas empresas. ${ }^{33}$ Ele enfatizou, entretanto, a necessidade de unidade da classe empresarial, protestando contra a "divisão de forças" causada pelo aparecimento da Acimpevi. Tais argumentos apareceram repetidamente na imprensa local: o secretário de imprensa da ACIB também foi o editor de uma coluna de ampla leitura que abordava as notícias de Blumenau de um dos principais jornais do estado, O Diario Catarinense. A Acimpevi encontrou pouca cobertura na mídia local.

Contudo, após um ano de existência, a Acimpevi reivindicou 4.500 membros pagantes em vinte vilas e cidades em todo o Vale do Itajaí. A organização criou seus membros com uma estratégia agressiva de confronto com autoridades locais e autoridades da ACIB, esforços bem-sucedidos em obter reconhecimento da mídia nacional, demandas populares por mais assistência do governo aos MPMEs e uma variedade de serviços disponíveis exclusivamente para os membros - todos provenientes de uma liderança altamente carismática e dedicada. A metade dos anos 1980 representou o ponto alto do ativismo da não-elite do capital, não apenas em Blumenau, mas em todo o país. ${ }^{34}$

A Terceira Onda: Em 28 de fevereiro de 1986, diante do início da inflação descontrolada, o Plano Cruzado do Presidente José Sarney congelou os preços e aumentou os salários reais, gerando um salto nos gastos dos consumidores. Sarney exortou as empresas brasileiras a tirar proveito do "fim da inflação" e da alta demanda do consumidor para investir no aumento da produção. Enquanto as taxas de juros dos bancos comerciais atingiram níveis de 50 a 80\%, os empréstimos patrocinados pelo governo para investimentos apresentavam baixas taxas

32 Entrevista pessoal do autor com Pedro Cascaes, presidente da Acimpevi, em 13 agosto de 1986, em Blumenau (SC).

33 "Empresariado do Vale do Itajaí está dividido na Acimpevi” em O Estado (Florianópolis, 29 de março de 1984); também ver "Décio Moser prega a união de todos" em O Povo (Blumenau, 29 de março de 1984).

34 Veja, por exemplo, William R. Nylen Representation without Participation: the Association of Small and MediumSized Businesses of Rio de Janeiro (Flupeme), Brazil (1985). 
mensais, de $2 \%$ a 5\%. O presidente do Banco Nacional de Desenvolvimento Econômico e Social (BNDES) afirmou que apenas pequenas empresas estavam realmente usando esses fundos para investir ${ }^{35 .} \mathrm{O}$ número de novas empresas iniciantes, principalmente microempresas, aumentou substancialmente. Mais fundos foram anunciados e funcionários do governo elogiaram as pequenas empresas por seu "patriotismo". A alta demanda dos consumidores fez com que a maioria das pequenas empresas prosperasse durante os nove meses em que o Plano Cruzado permaneceu em vigor.

O governo Sarney fez várias propostas públicas para os líderes das novas associações do MPME. Ele e seu ministro da economia, Dilson Funaro, se reuniram em ocasiões separadas com vários deles e receberam apoio qualificado para a "opção do mercado interno" do Plano Cruzado. ${ }^{36}$ Em março de 1986, Sarney convidou António Guarino, presidente da nova Associação de Pequenas e Médias Empresas do Rio de Janeiro (Flupeme), para se tornar presidente do Cebrae. Guarino foi o primeiro empresário, também o primeiro pequeno empresário, a presidir o Cebrae nos quatorze anos da sua existência. Os ativistas-proprietários do MPME ficaram entusiasmados. Os líderes das associações oficiais da classe empresarial ficaram furiosos.

Logo após as eleições de novembro de 1986, o Plano Cruzado - em grande parte responsável pela vitória do PMDB à época - terminou tão de repente quanto havia começado, revelando claramente os esforços politicamente motivados para mascarar suas instáveis fundações econômicas. À medida que a economia voltava à inflação e à recessão, a demanda do consumidor caía e as taxas de juros disparavam. Os proprietários endividados de MPMEs sofreram bastante. Uma pesquisa realizada em março de 1987 com 350 pequenas empresas no Rio de Janeiro indicou que as taxas de juros mensais dos empréstimos haviam subido para 18,3\% (as taxas mensais chegariam mais tarde a 30\%). Para piorar a situação, os bancos comerciais que até consideraram conceder novos empréstimos e reagendamentos exigiram acordos informais de "reciprocidade" (ou seja, ilegais) em que parte dos novos fundos teria que ser usada para "seguro" ou como um saldo mínimo exigido. ${ }^{37}$

O governo prometeu mais fundos para pequenas empresas, mas, no clima de crescente incerteza (Sarney estava trabalhando com seu terceiro ministro da economia em menos de três anos), a realidade ficou muito aquém. Em alguns casos, os fundos simplesmente não foram liberados pelas agências governamentais responsáveis. Quando os ministros da economia de Sarney e o Banco Central elaboraram um esquema de refinanciamento para as dívidas do Cruzado, muitos bancos privados se recusaram a cooperar. Funcionários do Banco Central

35 BNDES diz que só pequenos investem, Flupeme Notícias 15 (1986). Muitos grandes produtores hesitaram em parte por se preocupar com a sustentabilidade a longo prazo do plano e em parte porque as altas taxas de juros proporcionaram maiores retornos no setor financeiro da economia.

36 Ofereceram só “apoio qualificado" por causa da clemência do governo em não reprimir a contenção ilegal dos grandes negócios pelos controles de preços (cobrar um prêmio por mercadorias ou exigir um desconto de pequenos fornecedores, nenhum dos quais podia aparecer nos recibos de vendas), bem como estocagem ilegal e acordos de compra exclusivos de produtos escassos.

37 A pesquisa da Flupeme, Flupeme Notícias 20 (1987). 
admitiram que apenas 30\% dos elegíveis para assistência realmente a receberam. ${ }^{38}$ Para piorar a situação, pelo menos aos olhos dos líderes do movimento associativismo do MPME, Guarino foi destituído da presidência do Cebrae com menos de um ano de mandato.

Como a maioria dos brasileiros, muitos pequenos empresários se sentiram traídos pela transformação do mercado interno exuberante inspirado pelo Cruzado em estagflação cada vez pior. Para aqueles que contrataram empréstimos para aproveitar a aparente recuperação econômica, esse sentimento de traição foi agravado pela possibilidade real de perder seus negócios e bens pessoais. Nesse contexto, muitos buscaram conselhos.

Amaioria das entidades tradicionais da classe empresarial, ao mesmo tempo quedenunciou publicamente a "destrutividade" do plano, assumiu a linha-padrão de responsabilidade dos devedores: pague e seja mais inteligente da próxima vez, aproveite o esquema de refinanciamento do Banco Central ou liquide ativos e encontre um emprego. Essa também foi a atitude dos principais comentaristas da mídia. Para os proprietários do MPME que não encontraram consolo nessa sabedoria ortodoxa ("Por que eu pagaria quando o que aconteceu não foi minha culpa?"), a maioria dasassociações autônomas de pequenas empresasadotou uma postura pró-devedor mais agressiva.

Denunciando publicamente o comprometimento dos bancos privados dos esquemas oficiais de reescalonamento, muitos entraram com ações individuais contra bancos, amarrando o caso no sistema judicial por um ou dois anos. O devedor ficou, então, livre para continuar o melhor que pôde (obviamente, sem acesso ao crédito). Muitas vezes, os bancos preferiram resolver casos fora do tribunal em termos relativamente generosos. À medida que essas ações se tornavam cada vez mais conhecidas, a participação em associações autônomas aumentava.

As associações de pequenas e médias empresas se alegraram durante a redação, entre 1987 e 1988, da nova Constituição do Brasil (e depois se lamentaram). Seus líderes uniram-se em uma rara aliança com organizações empresariais tradicionais em favor do artigo 179, estabelecendo "tratamento jurídico diferenciado" para micro e pequenas empresas "com o objetivo de estimulálas pela simplificação de seus processos administrativos, fiscais, previdenciários e de crédito, bem como a eliminação ou redução de tais obrigações por meio de legislação". ${ }^{39}$ Com efeito, o artigo 179 tomou o espírito do Estatuto da Microempresa e o consagrou na nova Constituição. O ex-presidente da ACSP e deputado federal, Guillerme Afif Domingos, se proclamou em voz alta (e erroneamente) o autor do artigo 179 e a principal força política por trás de sua passagem. A maioria dos líderes de organizações empresariais tradicionais seguiu o exemplo ao reivindicar vitória por seus esforços em nome de seus membros-microempresas. A mídia tendia a reportar tais alegações sem questionar.

Infelizmente, em termos de sua imagem pública geral, a menção mais conhecida dos MPMEs na Constituição dizia respeito ao artigo 47 das “Cláusulas transitórias”, mais conhecido

38 Protesto contra o Banco Central, Flupeme Notícias 24 (1987).

39 Constituição da República Federativa do Brasil (1988), título VII, capítulo 1, Art. 179. Esse artigo foi finalmente regulamentado com a Lei n.8.864 de 28 de março de 1994. 
como "emenda de anistia". Essa cláusula isentou a maioria das micro e pequenas empresas, bem como as micro, pequenas e médias fazendas, de ter que ajustar pela inflação quaisquer empréstimos contratados durante o Plano Cruzado (no momento em que a inflação anual era de 934\% em 1988 e as falências dos MPMEs atingiram níveis recordes). Os beneficiários da anistia ainda tinham que pagar suas dívidas, mas apenas nos termos das taxas de juros pré-inflação originais. Com efeito, os beneficiários receberam uma anistia de suas responsabilidades legais como devedores para pagar o ônus da inflação pós-Cruzado.

Embora isso possa ter sido uma vitória para muitos proprietários de micro e pequenas empresas, o governo, as grandes empresas, as entidades tradicionais da classe empresarial e, mais importante, os formadores de opinião pública na mídia, viram as coisas de maneira muito diferente. A lei sagrada do contrato foi deliberadamente desobedecida por "devedores impulsivos" e "demagogos populistas irresponsáveis" no Congresso. Um precedente perigoso havia sido estabelecido. A reação foi rápida e furiosa. O quarto ministro da economia de Sarney, Maílson da Nóbrega, apresentou números alarmantes mostrando o quanto isso ia custar aos contribuintes. Sarney anunciou que os empréstimos agrícolas para o próximo ano seriam negados a micro, pequenos e médios agricultores. Os bancos declararam sua indisposição a emprestar para pequenas empresas "não confiáveis", definidas como aquelas que ousariam tirar vantagem da anistia. A mídia relatou essas declarações ampla e favoravelmente.

Embora os números do governo mais tarde tenham sido inflacionados, e a ameaça de Sarney tenha sido revogada, o dano permaneceu. Enquanto os MPMEs haviam sido retratados como heróis da economia popular versus a aliança "cartorial" do Estado e das grandes empresas dependentes, os pequenos empresários e suas associações representativas eram agora descritos na imprensa como cartorialistas egoístas, aproveitando descaradamente tendências populistas do Congresso às custas da sociedade como um todo. ${ }^{40} \mathrm{O}$ comentário a seguir, de um colunista popular, era um refrão típico:

A Assembléia Constituinte não foi inventada para votar em material episódico como a anistia da dívida para empresários falidos, enganados ou simplesmente astutos. [...] a anistia privatiza os lucros dos beneficiados e socializa as perdas dos credores. Amplia a ética política desses ilustres manipuladores profissionais de assuntos públicos (BETING, 1988, p. A-24).

Depois que a anistia e o furor passaram, e após seus beneficiários receberem seus perdões "vergonhosos", as pequenas empresas quase desapareceram da vista do público. O associativismo do MPME diminuiu, conforme indicado por um declínio constante na participação de associações de autônomos e pelo desaparecimento real de muitas associações.

40 “Cartorialismo" é definido e ilustrado em William R. Nylen em Liberalismo para todo mundo menos eu: o Brasil e a "solução" neoliberal (1992). É semelhante às "combinações redistributivas" mercantilistas no Peru, conforme descrito por DeSoto em The Other Path (1989). 
Uma exceção importante ocorreu em São Paulo, envolvendo um grupo chamado Associação Nacional de Empresas de Base (PNBE). A partir do fim de 1986, esse grupo de industriais de porte médio e mais jovem (entre 30 e 40 anos), com cargos de segundo nível na Fiesp, começou a se reunir informalmente para discutir questões como política macroeconômica, o papel da Fiesp na elaboração de políticas econômicas, e uma falta percebida de comunicação eficaz entre a liderança da Fiesp e as "bases" da classe empresarial (definidas explicitamente como micro, pequenas e médias empresas nacionais).$^{41} \mathrm{~A}$ maioria considerou que eles próprios haviam sido desprezados pela "máfia" da Fiesp em seus esforços para participar da formulação de políticas da elite do capital. Concluíram que a Fiesp precisava tanto de abertura quanto o restante das instituições políticas elitistas do Brasil. Nas palavras de um membro fundador:

\begin{abstract}
Nossa tarefa é ser democráticos na Fiesp, lutar pelo espaço político; tentar, a partir da posição de nossos próprios sindicatos, modificar a estrutura de tomada de decisão de maneira democrática e não corporativista. Nosso trabalho como líderes eleitos não consiste em emitir pronunciamentos e decisões, mas em permitir discussões e tomar decisões por meio de tais discussões. A tomada de decisão deve ser feita com transparência, não a portas fechadas (FEOLA, 1988). ${ }^{42}$
\end{abstract}

Em junho de 1987, o PNBE tornou pública uma declaração de princípios e uma série de reuniões públicas destinadas a empresários que achavam que não estavam recebendo o reconhecimento que mereciam do Estado (na forma de políticas econômicas relevantes) ou das entidades de classe tradicionais (em termos de representação). ${ }^{43}$ A maioria das pessoas que compareceram a essas reuniões era proprietária de um MPME, e estava irritada com a direção recessiva pós-Cruzado da formulação de políticas econômicas e com a abordagem da Fiesp, que nada fez por seus problemas. Esses eventos foram amplamente divulgados pela mídia e entrevistas com essa "facção de oposição" dentro da Fiesp apareceram em vários jornais e revistas importantes.

Embora o PNBE nunca tenha desafiado o direito da Fiesp de representar os industriais de São Paulo como um todo, desafiou diretamente a capacidade da liderança atual de fazê-lo de forma eficaz. Desinteressada em tais distinções, a liderança da Fiesp respondeu com ameaças, esforços de cooptação e tentativas disfarçadas de se entrincheirar por meio de mudanças nos

41 A maioria das informações sobre o PNBE vem de entrevistas pessoais com os membros fundadores: Oded Grajew (11 de janeiro de 1988), Fábio Starace Fonseca (27 de abril de 1988 e 2 de setembro de 1988), Joseph Michael Couri ( 3 de maio de 1988 e 29 de agosto de 1988), Emerson Kapaz (18 de maio de 1988), Bruno Nardini Feola (19 de maio de 1988), Paulo Roberto Butori (20 de maio de 1988) e Luiz Carlos Delben Leite (2 de junho de 1988 e 6 de dezembro de 1988). Esse é o único exemplo de ativismo do capital não-elite que se destacou na literatura sobre política de classe empresarial. Veja, por exemplo, Payne em Brazilian Industrialists (1994) e também Peter Kingstone, em Shaping Business Interesses (1994).

42 Entrevista pessoal com Bruno Nardini Feola, membro do PNBE e primeiro vice-presidente do SINDIMAQ, em 19 de maio de 1988, em São Paulo.

43 A declaração de princípios, intitulada PNBE: Mobilização Pela Defesa da Livre Iniciativa no Brasil, foi enviada como um comunicado de imprensa a todos os principais meios de comunicação. 
estatutos do governo da Fiesp, que descartariam desafios à liderança em exercício. No início de 1989, os membros do PNBE foram simplesmente dispensados de seus cargos, alguns dos quais foram eleitos. A maioria permaneceu ativa e visível, nas posições de liderança nos sindicatos setoriais. Em 1992, o membro do PNBE, Emerson Kapaz, montou uma campanha malsucedida e amargamente travada, para a presidência da Fiesp. ${ }^{44}$ A candidatura de Kapaz coroou a ascensão do PNBE à proeminência pública, ao mesmo tempo que dividiu seus membros (já enfraquecidos por uma crescente politização partidária de muitos de seus líderes mais visíveis). ${ }^{45}$ No final dos anos 1990, o PNBE evoluiu de seu foco inicial em fornecer uma voz forte e alternativa à nãoelite do capital, em questões de política-econômica, para se tornar um grupo de cidadania que promove discretamente questões de justiça social e reforma de políticas sociais.

Os esforços anteriores do PNBE para contestar as reivindicações de representação da Fiesp levaram um de seus membros a buscar uma estratégia paralela. Referindo-se à cláusula "tratamento diferenciado legal" (artigo 179) da nova Constituição, o industrial de médio porte Joseph Couri criou um novo sindicato: o Sindicato da Micro e Pequena Indústria do Estado de São Paulo (Simpi). ${ }^{46}$ O Simpi teria o mesmo acesso legal ao Imposto Sindicato - pago por todas as empresas formais em apoio à estrutura oficial de representação -, assim como os sindicatos mais antigos, garantindo uma sólida base financeira. Além disso, o novo sindicato e seus membros poderiam votar nas eleições da Fiesp e Ciesp. Durante anos, a Fiesp travou uma batalha perdida contra Couri e o Simpi nos tribunais e na mídia. Enquanto isso, Couri incentivou com sucesso a abertura de sindicatos similares de microindústria em todo o Brasil. O sucesso de Couri, no entanto, teve vida curta.

Um desafio finalmente debilitante para toda essa década e meia de esforços para promover o associativismo do MPME (ou, pelo menos, estabelecer uma alternativa para as grandes organizações dominadas pelas grandes empresas e sua liderança) começou com a proposta extinção do Cebrae, em 1990, como parte dos esforços de corte de orçamento do presidente Fernando Collor. ${ }^{47}$ Os funcionários do Cebrae se uniram a várias associações do MPME em um esforço para manter o Cebrae vivo. Incapazes de cooperar, no entanto, as associações autônomas perderam para um plano apresentado pela Confederação Nacional da Indústria, a organização

44 Para obter informações sobre o PNBE, no final dos anos 1980 e início dos anos 1990, consulte Kingstone em Shaping Business Interesses (1994).

45 Vários líderes do PNBE entraram no círculo interno de conselheiros de política econômica do Presidente Collor após sua campanha em que ele desprezou publicamente a liderança da Fiesp como de mente estreita e "cartorialista". Outros apoiaram ativamente o Partido dos Trabalhadores, de esquerda. Em meados dos anos 1990, vários líderes e ex-líderes do PNBE, incluindo Kapaz, ocupavam posições no governo do estado de São Paulo, dirigido por Mario Covas, do Partido da Social Democracia do Brasileira (PSDB).

46 A maioria das informações provêm de entrevistas citadas anteriormente com Joseph Couri. As ações de Couri não foram endossadas pelo restante do PNBE.

47 O Cebrae sobreviveu a uma ameaça semelhante na política de corte orçamentária do presidente Sarney, em 1988, intitulada "Operação Desmantelar". Ele acabou sendo salvo, embora seu orçamento tenha sido reduzido, pelo fato de seu então presidente, Paulo Lustosa, ser amigo pessoal do presidente. 
nacional das federações da indústria em nível estadual. ${ }^{48} \mathrm{O}$ novo Sebrae foi descentralizado e "corporativizado", isto é, entregue a um conselho executivo "não governamental", composto por entidades públicas responsáveis pelos programas de desenvolvimento do MPME - sempre incluindo representantes de bancos estaduais e federais de desenvolvimento e as federações locais da indústria e do comércio, e financiado principalmente por um novo imposto obrigatório de $0,3 \%$ sobre salários. ${ }^{49}$

O controle efetivo dos conselhos pelas organizações tradicionais de classe empresarial significava que a liderança dessa ditava essencialmente as metas e as alocações orçamentárias consideráveis dos 27 Sebraes em nível estadual. Somente o Sebrae do Rio de Janeiro incluiu uma associação autônoma de MPME (Flupeme) em seu conselho de governo (o conselho foi, entretanto, totalmente controlado pela federação da indústria desse estado, um inimigo de longa data do Flupeme). Os novos sindicatos da microindústria foram "representados" por federações que toleraram apenas relutantemente sua existência. Essa exclusão efetiva dos conselhos do Sebrae - que agora administram praticamente todos os esforços oficiais de desenvolvimento direcionados aos MPMEs - significa que a organização autônoma e a mobilização da não-elite do capital, para todos os efeitos, tornaram-se impossíveis.

\section{Análise}

A principal problemática deste artigo foi dupla: primeiro, a falta de representação política para cerca de $99 \%$ da classe empresarial brasileira e, segundo, a falta de qualquer análise acadêmica séria sobre esse problema. Não posso explicar o segundo problema, exceto ao observar que as análises da política da classe empresarial tradicionalmente se concentram nos interesses e ações das elites empresariais. Quanto ao problema da falta de representação dentro da classe empresarial, argumentei que a não-elite do capital no Brasil perdeu a oportunidade de se representar principalmente porque as organizações existentes da classe empresarial dominadas pelo capital nacional da elite lutaram por isso. Em outras palavras, a falta de representação do capital que não é de elite não ocorreu por causa de uma cultura política de não participação, generalizada para todos os brasileiros que não são de elite ou específica para proprietários de empresas menores, ou por falta de recursos efetivos de empreendedores políticos para traduzir os anseios desse "grupo latente" em organizações reais de ação coletiva. ${ }^{50}$ Pelo contrário, o associativismo de micro, pequenas e médias empresas foi notícia notável no Brasil por quase duas décadas.

48 Informações de entrevista pessoal com o presidente da Flupeme, Benito Paret, 22 de junho de 1993 (Rio de Janeiro); e de um funcionário de longa data, necessariamente anônimo, do Sebrae-RJ (anteriormente Ceag-RJ).

49 Veja a nota de rodapé de número 11.

50 Os conceitos de "empreendedor político" e "grupo latente" podem ser encontrados no tratamento dado por Mancur Olson à ação coletiva em grandes grupos, no livro The Logic of Collective Action; Public Goods and the Theory of Groups (1971). 
O poder das associações tradicionais de antecipar, cooptar ou destruir os desafios que não pertencem às elites, para sua efetiva monopolização da representação e seu atual domínio do Sebrae, mostram que o corporativismo excludente está bem vivo no Brasil contemporâneo. Pode-se ficar tentado a argumentar, no entanto, que os acordos colaborativos do Sebrae entre o Estado e a sociedade civil organizada - seu "embaçamento das fronteiras da sociedade estatal através da formulação conjunta de políticas" ${ }^{51}$ - constitui um exemplo progressivo de "corporativismo democrático", "concertação" ou "redes associativas".52 Certamente, há menos um controle centralizado do Estado e mais autonomia societal nos conselhos de governo do Sebrae, em comparação com as hierarquias burocráticas de cima para baixo do antigo Cebrae, durante os períodos de transição autoritária e no início da democracia. Mas o antipluralismo institucionalizado e a intolerância à "legitimidade da diferença" ${ }^{33}$-consistentemente exibida ao longo dos anos pela liderança das entidades tradicionais da classe empresarial, que agora dominam o Sebrae "em nome das" micro, pequenas e médias empresas - não têm nada a ver com a democracia. O que temos hoje não é um corporativismo democrático, mas praticamente o mesmo "sistema de expressão de interesse oficialmente patrocinado e protegido" que Phillipe Schmitter (1971, p. 222) encontrou no Brasil na década de $1960 .{ }^{54}$ De fato, Schmitter (1995) observou recentemente essa tendência infeliz à "incrustação" de antigas instituições corporativistas em muitas das novas democracias da América Latina. ${ }^{55}$

Se Adam Przeworski (1992, p. 116), entre outros, está correto ao argumentar que “a própria essência da democracia é a competição entre forças políticas com interesses conflitantes" ${ }^{56}$ então devemos concluir que o processo pelo qual a "unidade de classe empresarial" foi construído no Brasil prejudicou a democracia naquele país. Isso foi feito principalmente ao restringir severamente, se não eliminar, a competição e o debate pluralistas dentro da classe empresarial. Ao fazê-lo, também prejudicou a construção da cidadania democrática (ou seja, conscientização e participação política) entre uma parcela significativa da sociedade brasileira, desnudando, no processo, as fundações de classe e institucionais da chamada "cultura política" da não participação popular. $^{57}$

51 Scott Martin em Beyond Corporatism: New Patterns of Representation in the Brazilian Auto Industry (1997).

52 Samuel Valenzuela (1992, p. 86-87) define “corporativismo democrático" da seguinte forma: “... os conflitos e demandas sociais são tratados por meio de procedimentos previsíveis e amplamente aceitos que incluem todos os grupos relevantes, mas são, ao mesmo tempo, isolados dentro dos limites mais estreitos possíveis, em termos da especificidade das questões e dos atores estatais, políticos e sociais envolvidos". "Concertação" é, essencialmente, a mesma coisa. O conceito de "redes associativas" é definido como "um tipo novo e não hierárquico de estrutura de representação (geralmente envolvendo atores populares), na qual atores estatais e sociais se unem para moldar as políticas públicas". (MARTIN, 1992, p. 69).

53 O’Donnell (1992, p. 43).

54 Philippe C. Schmitter em Interest Conflict and Political Change in Brazil (1971, p. 222).

55 Philippe C. Schmitter em Transitology: The Science or the Art of Democratization? (1995, p. 24-27).

56 Adam Przeworski em The Games of Transition (1992, p. 116).

57 Discutido, por exemplo, por José Álvaro Moisés em Dilemas da Consolidação Democrática no Brasil (1989, p. 168-171). 
Essa história da ascensão e da queda da ação coletiva da não-elite do capital no Brasil exibe muitas semelhanças com o padrão de "ciclo de protesto" dos movimentos sociais discutido por Sidney Tarrow (1994). ${ }^{58}$ Tarrow argumenta que novas formas de organização não elite e ativismo político surgem durante períodos de conflitos intraelite extraordinariamente intensos, muitas vezes provocados por graves crises econômicas (por exemplo, o desaparecimento do grande modelo desenvolvimentista liderado pelo Estado) e/ou mudança de regime político (por exemplo, abertura democrática). Esse conflito gera rachaduras e fissuras em instituições dominadas pela elite e redes informais (por exemplo, organizações tradicionais de classe empresarial), criando oportunidades para ativistas de fora da elite propagarem uma agenda e mobilizarem apoio. Como os primeiros ativistas (por exemplo, a primeira onda de associativismo da não-elite do capital) atraem a atenção da mídia e obtêm ganhos mais ou menos significativos para si mesmos, outros seguem o exemplo, criando, em conjunto, o "despertar da sociedade civil” tão frequentemente verificado pelos observadores dos processos de democratização.

Tarrow (1994) aponta como esse despertar pode criar tensões dentro dos novos movimentos entre radicais maximalistas e os moderados que jogam de acordo com as regras. Tais tensões dividem os novos movimentos da não-elite do capital, ao mesmo tempo que produzem uma unificação defensiva. Ao democratizar o Brasil - como na maior parte da América Latina - essas tensões foram atenuadas pelo fato de a moderação ter sido a regra esmagadora dos movimentos sociais contemporâneos. Segundo Tarrow (1994), a vitória da liderança moderada da não-elite move o lugar da luta política da sociedade civil para arenas institucionalizadas da política (por exemplo, partidos, legislaturas, burocracias estatais) que são facilmente "apadrinhadas" ou recuperadas por uma aliança intraelite cada vez mais unificada.

A barganha nessas arenas da política abre aos recém-chegados, não pertencentes à elite, toda uma gama de táticas-padrão da elite: repressão, cooptação de líderes e deslegitimação ou apropriação grosseira de seus programas. Tendo escolhido essa estratégia, o melhor que as organizações de movimentos sociais, que seguem as regras, pode esperar, segundo Tarrow (1994), são "reformas modestas", níveis modestos de participação cidadã comum e uma probabilidade modesta de sobrevivência organizacional ("modesta", isto é, relativa aos objetivos e demandas dos ativistas originais do movimento).

A estrutura analítica de Tarrow (1994) apoia claramente o argumento de que o ativismo político do MPME foi frustrado "de cima" por elites empresariais temporariamente divididas e depois reunificadas. Além disso, sugere que a razão pela qual o ativismo do MPME ocorreu foi que os conflitos intraelite enfraqueceram as elites empresariais e reduziram temporariamente sua capacidade de exclusão. ${ }^{59}$ Por fim, podemos deduzir, a partir da análise do autor, que o impacto do ativismo da não-elite do capital incluiu a implementação de reformas modestas

58 Sidney Tarrow em Power in Movement (1994, p. 153-86).

59 Isso foi confirmado em minha análise do caso mais bem-sucedido de associativismo do MPME, a Flupeme do Rio de Janeiro, em Nylen (1995). 
que, apesar de ficarem abaixo das expectativas dos próprios ativistas, representaram ganhos significativos em relação ao status quo anterior.

Os ativistas da não-elite do capital no Brasil articularam uma visão do futuro desenvolvimento econômico de seu país muito diferente do modelo atual de inspiração neoliberal ou do modelo de grandeza desenvolvimentista anterior. Ele incorporou o "tratamento diferenciado" para os MPMEs em uma "opção para o mercado interno" com foco no consumo popular e na produção nacional, estimulando o primeiro com uma distribuição de renda mais justa (por exemplo, salários-mínimos mais altos, tributação progressiva e programas sociais ampliados) e esse último com incentivos fiscais e de crédito seletivos, proteção seletiva da indústria nascente contra a concorrência estrangeira e legislação antitruste eficaz. Em vez disso, o que eles obtiveram foram "reformas modestas", como mudanças favoráveis ao MPME nos processos de negociação trabalhista. Os departamentos de assistência do MPME acrescentaram, à maioria das organizações empresariais tradicionais, o Estatuto da Microempresa - que proporciona alívio tributário e regulatório para os menores dos menores - do artigo 197 da Constituição de 1988, que consagra legalmente o princípio de "tratamento diferenciado" para micro e pequenas empresas e (por todas as suas falhas políticas) um órgão assistencialista do MPME muito mais bem financiado e visível: o Sebrae.

No que diz respeito a essas melhorias, não tão boas como deveriam (aos olhos dos ativistas originais), mas ainda significativas, se comparadas com o status quo antes de 1978, é provável que nenhuma teria sido implementada se não houvesse a existência da "ameaça" do ativismo político da não-elite do capital na mobilização de um número significativo de micro, pequenos e médios empresários do Brasil para ingressar em organizações autônomas que desafiaram diretamente as organizações de classe empresarial já existentes. O registro comparativo mostra que reformas, mesmo modestas, devem ser travadas a partir "de baixo" e raramente surgem "de cima”, das ações esclarecidas ou benevolentes das elites. ${ }^{60}$

\section{Conclusão}

A literatura sobre a política da classe empresarial na América Latina e o registro histórico dos processos de democratização da região sofrem com a falha em considerar adequadamente a política da não-elite do capital. O estudo de caso apresentado aqui - referente à ascensão e à queda do ativismo político entre empresários das MPMEs no Brasil “em vias de democratização" - ilustra importantes observações obscurecidas por falta acadêmica.

Primeiro, ilustra claramente a posição social e politicamente subordinada dos micro, pequenos e médios empresários em relação aos chamados "líderes empresariais",

60 Esta é uma conclusão-chave, por exemplo, em Dietrich Rueschemeyer, Evelyne Huber Stephens \& John D. Stephens Capitalist Development \& Democracy (1992). 
encontrados nas tradicionais associações dominadas pela elite. Em segundo lugar, e talvez o mais importante, o estudo de caso sugere que esses mesmos "líderes empresariais" negaram os princípios democráticos fundamentais de contestação e inclusão ao criar uma "unidade de classe empresarial" retórica, reconstruindo à força as instituições corporativistas excludentes dominadas pela elite e destruindo expressões autônomas de ação coletiva não pertencentes à elite. Isso tem implicações negativas para os processos gerais de democratização.

Finalmente, o estudo de caso ilustra a utilidade do conceito de Sidney Tarrow (1994) de um "ciclo de protesto", mostrando como a ascensão e a queda da ação coletiva da não-elite do capital no Brasil podem ser vistas como partes de um processo cíclico, mais universal, de reformismo induzido pela crise, seguido de eventual enrijecimento das estruturas políticas.

\section{Referências}

A PESQUISA da Flupeme. Flupeme Notícias, Rio de Janeiro, ed. 20, p. 4, mar. 1987.

BARTELL, Ernest; PAYNE, Leigh A. (ed.). Business and democracy in Latin America. Pittsburgh: University of Pittsburgh Press, 1995.

BECKER, David G. Business Associations in Latin America: the Venezuelan Case. Comparative Political Studies, v. 23, n.1, p. 114-138, abr. 1990.

BELTRÃO, Helio. Descentralização e Liberdade. Rio de Janeiro: Editora Record, 1984.

BETING, Joelmir. A Ficção Capitalista, Folha de São Paulo, p. A-24, 1 jul. 1988.

BNDES diz que só pequenos investem. Flupeme Notícias, Rio de Janeiro, ed. 15, p. 4, jul./ago. 1986.

BOSCHI, Renato Raul. Elites Industriais e Democracia. Rio de Janeiro: Editora Graal, 1979.

CEBRAE. Política de Desenvolvimento das MPMEs. Anexo estatístico. Brasília, ago. 1985.

CHALMER, Douglas A.; SOUZA, Maria do Carmo Campello; BORON, Atilio A. (ed.). The Right and Democracy in Latin America. New York: Praeger, 1992.

DÉCIO Moser prega a união de todos. O Povo, Blumenau, 29 mar. 1984.

DE SOTO, Hernando. The Other Path. New York: Harper \& Row Publishers, 1989.

DINIZ, Eli; BOSCHI, Renato Raul. Empresariado Nacional e Estado no Brasil. Rio de Janeiro: ForenseUniversitária, 1978.

DINIZ, Eli; BOSCHI, Renato Raul. O Programa de Apoio à Pequena e Média Empresas no BNDES: Análise, Avaliação e Perspectivas. In: DINIZ, Eli (org.) A Pequena e Média Empresa no Atual Modelo de Desenvolvimento Econômico. Rio de Janeiro: IUPERJ, 1980. p. 229-95.

EMPRESARIADO do Vale do Itajaí está dividido na Acimpevi. O Estado, Florianópolis, 29 mar. 1984.

EVANS, Peter. Dependent Development: The Alliance of Multinational, State, and Local Capital in Brazil. Princeton: Princeton University Press, 1979.

FIGUEIRA, Archibaldo. O Legislativo e o Sistema de Pequena e Média Empresa. ENCONTRO DE COMUNICAÇÃO SOCIAL DO SISTEMA CEBRAE, 1., 1986, A PME em Questão. Brasília, 1986.

HAGOPIAN, Francis. Traditional Power Structures and Democratic Governance in Latin America. In: DOMÍNGUEZ, Jorge I.; LOWENTHAL, Abraham R. (ed.). Constructing Democratic Governance: Latin America and the Caribbean in the 1990s. Themes and Issues. v. 3. Baltimore: Johns Hopkins University Press, 1996. p. 64-86. 
HEREDIA, Blanca. Profits, Politics, and Size: The Political Transformation of Mexican Business. In: CHALMERS, Douglas; SOUZA, M.; BORÓN, Atilio. (ed.). The Right and Democracy in Latin America. New York: Praeger, 1992. p. 277-302.

Jornal da Tarde. São Paulo, p. 10, 16 ago. 1985.

KECK, Margaret E. The Workers' Party and Democratization in Brazil. New Haven, CT: Yale University Press, 1992.

KINGSTONE, Peter. Shaping Business Interests: the Politics of Neoliberalism in Brazil, 1985-1992. 1994. Tese (Doutorado em Ciência Política) - University of California at Berkeley, Califórnia, 1994.

MAINWARING, Scott; O’DONNELL, Guillermo; VALENZUELA, Samuel (ed.). Issues in Democratic Consolidation: The New South American Democracies in Comparative Perspective. Notre Dame: University Notre Dame Press, 1992.

MARTIN, Scott. Beyond Corporatism: New Patterns of Representation in the Brazilian Auto Industry. In: CHALMERS, Douglas; SOUZA, M.; BORÓN, Atilio. (ed.). The Right and Democracy in Latin America. New York: Praeger, 1992. p. 45-71.

MISÉRIA e Classe Média. Folha de São Paulo, São Paulo, 29 out. 1997.

MOISÉS, José Álvaro. Dilemas da consolidação democrática no Brasil. Lua Nova, São Paulo, n. 16, p. 47-86, mar. 1989.

NOGUEIRA, Oracy Nogueira et al. O Empresário Industrial Paulista Frente à Federação e ao Centro das Indústrias do Estado de São Paulo. São Paulo: CIESP: Fundação Instituto de Pesquisas Econômicas: Faculdade de Economia e Administração da Universidade de São Paulo, 1975.

NYLEN, William R. Small business owners fight back: non-elite capital activism “democratizing Brazil”. 1992. Tese (Doutorado em Ciência Política) - Columbia University, Nova Iorque, 1992.

NYLEN, William R. Representation Without Participation: the Association of Small and Medium-Sized Businesses of Rio de Janeiro (Flupeme), Brazil. INTERNATIONAL CONGRESS, LATIN AMERICAN STUDIES ASSOCIATION, 19., 1995. Washington, DC, 28-30 set. 1995.

NYLEN, William R. Liberalismo para todo mundo menos eu: Brazil and the Neoliberal “Solution”. In: CHALMERS, Douglas; SOUZA, M.; BORÓN, Atilio. (ed.). The Right and Democracy in Latin America. New York: Praeger, 1992. p. 259-276.

O’DONNELL, Guillermo. Transitions, Continuities, and Paradoxes. In: MAINWARING, Scott; O’DONNELL, Guillermo; VALENZUELA, Samuel (ed.). Issues in Democratic Consolidation: The New South American Democracies in Comparative Perspective. Notre Dame: University Notre Dame Press, 1992. p. 17-56.

OLSON, Mancur. The Logic of Collective Action: Public Goods and the Theory of Groups. Cambridge: Harvard University Press, 1971.

PAYNE, Leigh A. Brazilian Industrialists and Democratic Change. Baltimore: Johns Hopkins University Press, 1994.

PNBE. Mobilização Pela Defesa da Livre Iniciativa no Brasil. São Paulo, jun. 1987.

PROTESTO contra o Banco Central. Flupeme Notícias. Rio de Janeiro, ed. 24, p. 5, jul. 1987.

PRZEWORKI, Adam. The Games of Transition. In: MAINWARING, Scott; O'DONNELL, Guillermo; VALENZUELA, Samuel (ed.). Issues in Democratic Consolidation: The New South American Democracies in Comparative Perspective. Notre Dame: University Notre Dame Press, 1992. p. 105-152.

RATTNER, Henrique (org.). Pequena Empresa: O Comportamento Empresarial na Acumulação e Luta pela Sobrevivência. v. 1 e 2. São Paulo: Brasiliense, 1985. 
RIGHETTO, Wlademir et al. O pequeno industrial é, antes de tudo, um forte ... candidato ao enfarte! Campinas, 1975. Mimeografado.

RUESCHEMEYER, Dietrich; STEPHENS, Evelyne Huber Stephens; STEPHENS, John D. Capitalist Development \& Democracy. Cambridge: Polity Press, 1992.

SCHMITTER, Philippe C. Interest Conflict and Political Change in Brazil. Stanford: Stanford University Press, 1971.

SCHMITTER, Philippe C. Transitology: The Science or the Art of Democratization? In: TULCHIN, Joseph S.; ROMERO, Bernice (ed.) The Consolidation of Democracy in Latin America. London: Lynne Rienner Publishers, 1995. p. 11-41.

SHADLEN, Kenneth C. Small Industry and the Mexican Left: Neoliberalism, Corporatism, and Dissident Populism. ANNUAL MEETING OF THE AMERICAN POLITICAL SCIENCE ASSOCIATION. Whashington, DC, 28-31 ago. 1997.

TARROW, Sidney. Power in Movement: Social Movements, Collective Action and Politics. New York: Cambridge University Press, 1994.

VALENZUELA, Samuel. Democratic consolidation in post-transicional settings: notion, proccess, and facilitating conditions. In: MAINWARING, Scott; O’DONNELL, Guillermo; VALENZUELA, Samuel (ed.). Issues in Democratic Consolidation: The New South American Democracies in Comparative Perspective. Notre Dame: University Notre Dame Press, 1992. p. 57-104.

VELASCO E CRUZ, Sebastião. Empresários, Economistas e perspectivas da Democratização no Brasil. In: REIS, Fábio Wanderley; O’DONNELL, Guillermo (org.). A Democracia no Brasil: Dilemas e Perspectivas. São Paulo: Vértice, 1988. p. 256-281.

VILAS, Carlos M. Participation, Inequality, and the Whereabouts of Democracy. In: CHALMERS, Douglas A. et al. (ed.). The New Politics of Inequality in Latin America: Rethinking Participation and Representation. New York: Oxford University Press, 1997. p. 3-42.

Recebido em 09/03/2020

Aceito em 16/02/2021 